\title{
Outcomes of Percutaneous Nephrolithotomy Versus Open Stone Surgery for Pateints with Staghorn Calculi: Safety and Efficacy
}

\author{
Mohamed K Saif El-nasr ${ }^{1}$ MD; Hesham A. EL-Helaly ${ }^{1}$ MD; Hesham M. El Sayed ${ }^{1}$ MSc; Hamada A. \\ Youssof ${ }^{1}$ MD; Khaled Mohyelden ${ }^{1}$ MD
}

* Corresponding Author:

Mohamed K Saif El-nasr

mk_saifelnasr@yahoo.com

Received for publication April 26, 2020; Accepted November 1, 2020; Published online November 1, 2020.

\section{Copyright 2020 The Authors published by Al-Azhar University, Faculty of Medicine, Cairo, Egypt. All rights reserved. This an open-access article distributed under the legal terms, where it is permissible to download and share the work provided it is properly cited. The work cannot be changed in any way or used commercially.}

doi: 10.21608/aimj.2020.28759.1207

${ }^{1}$ Department of Urology , Fayoum University, Fayoum.

Disclosure: The authors have no financial interest to declare in relation to the content of this article. The Article Processing Charge was paid for by the authors.

Authorship: All authors have a substantial contribution to the article.

\begin{abstract}
BACKGROUND: The wide use of minimally invasive techniques in the management of multiple renal stones and staghorn stones have .replaced the open technique in last 30 year

But the Open techniques for the management of complex multiple and staghorn renal stones are still a viable option that should be considered in treating patients complex staghorn stones with large burden. In this study, we compare outcomes of Percutaneous Nephrolithotomy (PNL) Versus Open Stone Surgery (OSS) for patients with Staghorn calculi at the urology department Fayoum university hospital, in terms of efficacy, safety, operative procedure, intraoperative and postoperative complications.

METHODS: This is a prospective randomized study performed on 50 patients divided into OSS group and PNL group (25 patients for each group) during the period from December 2018 to January 2020. Perioperative assessment and investigations were done. Intraoperative and postoperative morbidity, operative time, hospital stay, and stone clearance at discharge home and follow-up were compared for both techniques. Follow up was completed for all cases with a mean duration 2 months.
\end{abstract}

Results: Stone-clearance was higher in OSS group (92\%) versus (84\%) in PNL group with no significant difference. Mean operative creatinine rise in OSS group was $(0.19 \pm 0.1 \mathrm{mg} / \mathrm{dl})$ and in PNL group was $(0.14 \mathrm{mg} / \mathrm{dl} \pm 0.07 \mathrm{mg} / \mathrm{dl})$. There is statistically significant creatinine rise with p-value $<0.05$ in OSS group. Mean operative hemoglobin loss in OSS group was $(1.5 \pm 0.85 \mathrm{mg} / \mathrm{dl})$ and in PNL group was $(1.65 \pm$ $0.90 \mathrm{mg} / \mathrm{dl})$ with no significant difference. Intraoperative complications was (28\%) in OSS group and included significant bleeding in (16\%) and pleural injury in (12\%) and in PNL group was (24\%) and included bleeding (12\%) and renal pelvis injury (12\%) with no significant difference. Regarding post operative complications OSS group showed (36\%) postoperative complications and PNL group showed (24\%) post operative complications. Operative time was significantly shorter for OSS $(131 \pm 10 \mathrm{~min})$ than for PNL $(174 \pm 14.9 \mathrm{~min})$ with p value 0.001 . Post operative hospital stay was significantly shorter in PNL Group (3.92 \pm 1.3 days) versus OSS group (5.88 \pm 1.2 days). Recovery time was significantly shorter $(2.33 \pm 0.48$ weeks) for PNL cases versus (4.48 \pm 0.71 weeks) for OSS cases .

Conclusions: PNL is a valuable treatment option for staghorn stones with a stone free rate approaching that of open surgery. Also it has less morbidity, with shorter hospital stay and earlier returns to work.

Key words: Staghorn stones; PNL; OSS.

\section{INTRODUCTION}

Staghorn stones are large branching stones that occupy part or all of the pelvicalyceal system. It is classified to complete or partial according to degree of occupancy of the collecting system. ${ }^{1}$

Staghorn' term describes the configuration of stone, and don't give information about stone composition. ${ }^{2}$
Nowadays the in developed countries the incidence of staghorn stones from the entire urinary stones decreased to $4 \%$, due to early and effective management of renal stones. ${ }^{3}$

Staghorn stones are infectious stones in $49-68 \%$ of cases and, therefore some physicians referred the staghorn term to stuvite stone. ${ }^{4}$

Staghorn stones need prompt assessment and treatment, as it has significant morbidity and 
potential mortality. Conservative management for this type of stones has $36 \%$ risk of developing significant renal impairment and mortality rate of $28 \%$ in 10 -year period.

Therefore, staghorn stones considered a significant disease entity that should be treated aggressively and effectively. ${ }^{5}$

Open stone surgery for staghorn calculi was considered the "gold standard" technique for other treatment options to be compared. However, advances in urological armamentarium have reduced its use. $^{6}$

PNL considered as the first-line therapy for most staghorn stones, according to the American Urological Association (AUA) guidelines. However some urologist still considered OSS as an acceptable option for management of complete staghorn stones. ${ }^{2}$

In this work, we try to compare the outcomes of OSS and PNL in the management of staghorn stones.

\section{PATIENT AND MATERIALS}

This is a prospective randomized comparative study conducted in the urology department in ElFayoum University Hospital. During the period between December 2018 and January 2020, 50 eligible patients were randomized using computergenerated block randomization with block size of 2 with 1:1 allocation ratio in either OSS group or PNL group .

Sample size calculated using G-Power software version 3.1.7 (Institute of experimental psychology, Heinrich Heine University, Dusseldorf, Germany). Minimal sample size of patients was 20 in each group needed to get power level 0.80 , alpha level 0.05 . With estimated $10 \%$ loss, 44 patients or 22 patients per group were required to provide a $90 \%$ power for the study. We increased the total sample size to 50 to allow for a margin for error. In this study, cases with renal staghorn stones were included regardless the age, sex, and the previous history of stone surgery. Only, cases with uncorrected coagulopathies, skeletal deformities, or active UTI were excluded from this trial. This trial has been reviewed and approved by our institutional review committee.

All participant patients signed a written consent. All patients were underwent routine preoperative preparation. Preoperative radiological studies were done in the form of plain $\mathrm{x}$-ray urinary tract film (PUT) and non-contrast computed tomography (NCCT) with or without intravenous urography (IVU) to estimate stone characteristics, anatomical abnormalities and degree of hydronephrosis .

In OSS group, under general anaesthesia, the patient was positioned in flank position. Intercostal or transcostal incision was done according to surgical plan. After dissection of the kidney, the upper ureter was looped. Starting from the ureter, the renal pelvis and the pedicle were dissected to be ready for warm ischemia if needed and to start stone extractition. The pelvis was then incised with scalpel then Potts scissors in an open U-shape lengthened to reach the lowest and the highest calyx avoiding the ureteropelvic junction. Then we mobilized the stones by curved stone forceps to free it from the pelvic urothelium and was extracted by forceps with rotational movements. Radial nephrotomies might be used for complete stone removal. For anatrophic nephrolithotomy, ice slush was placed around for 20 minutes, $100 \mathrm{ml}$ of $20 \%$ mannitol was infused and renal pedicle was clamped. Incision was done in the avascular Brodel's plane. After stone removal, repeated irrigation by saline for the collecting system was done and intraoperative $\mathrm{X}$-ray was used to assess for any residual stone. The ureter was stented, pelvicliceal system was closed and retroperitoneal and urethral catheter were fixed .

In PNL cases, under general anesthesia, cystoscopy and placement of a ureteric catheter were done in lithotomy position. In prone position, contrast was injected opacifying the collecting system to select the entry route for the percutaneous access. In case of planned multiple tracts, the calyces were punctured before dilatation. Serial dilatation till $30 \mathrm{Fr}$ was done using metallic Alken dilators. Nephroscopy was done using the 26Fr rigid long nephroscope (percutaneous nephroscope, KarlStorz, Tuttlingen, Germany) and stone fragmentation was done using pneumatic lithoclast (Al-Mottaheda, Cairo, Egypt). Following extraction of stone fragments, DJ stent and nephrostomy tube (Amicath, Cairo, Egypt) were fixed. Due to large stone burden, stent and nephrostomy were fixed in all patients for fear of significant residual stones and for tamponading.

In the night of surgery, vital signs, complete blood count (CBC) and serum cretinine were measured. In the first day postoperative plain KUB and or US was done to check the position of tubes and if there are residual stones. All patients were followed for, at least, two months after discharge. Antibiotics were administered to all patients according to culture and sensitivity

Operative time, blood loss, stone-free rates, hospital stay, intraoperative and postoperative complications (post operative complications classified according to modified Clavien-Dindo classification) and time to return to the patients' ordinary activities were calculated, plotted in a database and statistically analyzed .

Statistical analysis was done using SPSS software statistical computer package version 18 (SPSS Inc, USA). Data were expressed as mean \pm standard deviation (SD) or number (\%). For analysis of quantitative data, student t-Test was used for independent groups and Paired t-test was used for dependent groups of data. For analysis of qualitative data, Chi square or Fisher`s exact tests were used. The P-value $<0.05$ was considered the cut-off value for significance. 


\section{RESULTS}

Patient`s characteristics were presented in (Table-1). There was no statistically significant difference between both groups regarding age, sex, BMI, comorbidities and urologic surgical history, (p-value $>0.05$. (

The stone characteristics are shown in (Table-2). In this study, complete staghorn stones represented (24\%) in OSS group and (20\%) in PNL group while partial staghorn stones represented (67\%) in OSS group and (80\%) in PNL group with no significant difference.

In OSS group, the used technique was extended pelolithotomy in 20 cases, pyelolithotomy plus one or two nephrotomies in 4 cases and anatrophic nephrolithotomy in 1 case. In PNL group, the access was achieved through one punctured calyx in 22 cases and through two calyces in 3 cases.
There is statistically significant difference between both groups regarding to the operative time with shorter duration for OSS group (131.48 min +10.2) vs $(174.63 \mathrm{~min}+14.9)$ (p-value $<0.001$. (

Mean creatinine rise in OSS group was $(0.19 \pm 0.1$ $\mathrm{mg} / \mathrm{dl})$ and in PNL group was $(0.14 \pm 0.07 \mathrm{mg} / \mathrm{dl})$ which was statistically significant $(\mathrm{p}$-value $=0.04)$. Regarding mean operative $\mathrm{Hb}$ loss, it was (1.5 \pm 0.85 $\mathrm{mg} / \mathrm{dl})$ in OSS group versus $(1.65 \pm 0.90 \mathrm{mg} / \mathrm{dl})$ in PNL group with no significant difference (Table-7 .( There is no statistically significant difference between study groups as regards the different complications, either intraoperative or postoperative and also according to modified Clavien postoperative grades of complications (Table-8.(

Stone-clearance in OSS group was (92\%) and in PCNL group was (84\%) with no significant difference.

Hospital stay and recovery time were significantly shorter in PNL group than in OSS group.

\begin{tabular}{|c|c|c|c|c|c|c|}
\hline Variables & \multicolumn{2}{|c|}{$\begin{array}{c}\text { Group I } \\
\text { OSS (n=25) }\end{array}$} & \multicolumn{2}{|c|}{$\begin{array}{c}\text { Group II } \\
\text { PCNL(n=25) }\end{array}$} & p-value & Sig \\
\hline $\begin{array}{l}\text { Age (years) } \\
\text { (mean+SD) }\end{array}$ & 44.1 & 16.9 & 43.5 & 14.6 & 0.9 & NS \\
\hline $\begin{array}{l}\mathrm{BMI}\left(\mathbf{k g} / \mathbf{m}^{2}\right) \\
(\mathbf{m e a n}+\mathrm{SD})\end{array}$ & 21.4 & 1.4 & 20.8 & 1.7 & 0.2 & NS \\
\hline \multicolumn{7}{|c|}{$\begin{array}{c}\text { Sex } \\
\mathbf{N}(\%)\end{array}$} \\
\hline Male & 9 & $36 \%$ & 14 & $56 \%$ & 0.3 & NS \\
\hline Female & 16 & $64 \%$ & 11 & $44 \%$ & & \\
\hline \multicolumn{7}{|c|}{$\begin{array}{l}\text { Medical history } \\
\text { N (\%) }\end{array}$} \\
\hline Free & 18 & $72 \%$ & 18 & $72 \%$ & 0.8 & NS \\
\hline DM & 2 & $8 \%$ & 1 & $4 \%$ & & \\
\hline HTN & 5 & $20 \%$ & 6 & $24 \%$ & & \\
\hline \multicolumn{7}{|c|}{$\begin{array}{l}\text { Surgical history } \\
\text { N (\%) }\end{array}$} \\
\hline Free & 18 & $72 \%$ & 20 & $80 \%$ & 0.06 & NS \\
\hline $\begin{array}{c}\text { Ipsilateral open stone } \\
\text { surgery }\end{array}$ & 1 & $4 \%$ & 4 & $16 \%$ & & \\
\hline $\begin{array}{l}\text { Ipsilateral endoscopic } \\
\text { stone surgery }\end{array}$ & 6 & $24 \%$ & 1 & $4 \%$ & & \\
\hline
\end{tabular}

Table 1: Comparisons of demographic characters for both groups. 


\begin{tabular}{|c|c|c|c|c|c|c|}
\hline Variables & \multicolumn{2}{|c|}{$\begin{array}{c}\text { Group I } \\
\text { OSS }(\mathbf{n}=25)\end{array}$} & \multicolumn{2}{|c|}{ Group II } & p-value & Sig. \\
\hline \multicolumn{7}{|c|}{ Side N (\%) } \\
\hline Right & 10 & $40 \%$ & 15 & $60 \%$ & \multirow[t]{2}{*}{0.3} & \multirow[t]{2}{*}{ NS } \\
\hline Left & 15 & $60 \%$ & 10 & $40 \%$ & & \\
\hline \multicolumn{7}{|c|}{$\mathbf{N}(\%)$} \\
\hline Complete staghorn & 6 & $24 \%$ & 5 & $20 \%$ & \multirow[t]{2}{*}{0.9} & \multirow[t]{2}{*}{ NS } \\
\hline Partial staghorn & 19 & $76 \%$ & 20 & $80 \%$ & & \\
\hline No & 2 & $8 \%$ & 2 & $8 \%$ & \multirow[t]{4}{*}{0.9} & \multirow[t]{4}{*}{ NS } \\
\hline Mild & 12 & $48 \%$ & 10 & $40 \%$ & & \\
\hline Moderate & 9 & $36 \%$ & 10 & $40 \%$ & & \\
\hline Marked & 2 & $8 \%$ & 3 & $12 \%$ & & \\
\hline $\begin{array}{l}\text { Longest diameter (cm) } \\
\text { (mean+SD) }\end{array}$ & 5.74 & 0.60 & 5.86 & 0.63 & 0.5 & NS \\
\hline
\end{tabular}

Table 2: Comparisons of Kidney and stone characters for both groups.

\begin{tabular}{|c|c|c|c|c|c|c|}
\hline \multirow[t]{3}{*}{ Variables } & \multirow{2}{*}{\multicolumn{2}{|c|}{$\begin{array}{c}\text { Group I } \\
\text { OSS (n=25) }\end{array}$}} & \multicolumn{2}{|c|}{ Group II } & \multirow[t]{3}{*}{ p-value } & \multirow[t]{3}{*}{ Sig. } \\
\hline & & & PCN & 25) & & \\
\hline & Mean & SD & Mean & SD & & \\
\hline Operation time (min) & 131.48 & 10.2 & 174.63 & 14.9 & $<0.001$ & HS \\
\hline Creatinine change & 0.19 & 0.1 & 0.14 & 0.07 & $0.04 *$ & S \\
\hline Hemoglobin loss & 1.50 & 0.85 & 1.65 & 0.90 & 0.5 & NS \\
\hline
\end{tabular}

Table 3: Comparisons of operative time and perioperative laboratory changes in different study groups. 


\begin{tabular}{|c|c|c|c|c|c|c|}
\hline \multirow[t]{3}{*}{ Variables } & \multirow{2}{*}{\multicolumn{2}{|c|}{$\begin{array}{c}\text { Group I } \\
\text { OSS (n=25) }\end{array}$}} & \multirow{2}{*}{\multicolumn{2}{|c|}{$\begin{array}{c}\text { Group II } \\
\text { PCNL(n=25) }\end{array}$}} & \multirow[t]{3}{*}{$\mathrm{p}$-value } & \multirow[t]{3}{*}{ Sig. } \\
\hline & & & & & & \\
\hline & No. & $\%$ & No. & $\%$ & & \\
\hline \multicolumn{7}{|c|}{ Intraoperative complications } \\
\hline No & 18 & $72 \%$ & 19 & $76 \%$ & \multirow[t]{3}{*}{0.9} & \multirow[t]{3}{*}{ NS } \\
\hline Bleeding & 4 & $16 \%$ & 3 & $12 \%$ & & \\
\hline Pleural injuries & 3 & $12 \%$ & 0 & $0 \%$ & & \\
\hline Renal pelvis injury & $\cdots \cdots$ & $\cdots \cdots$ & 3 & $12 \%$ & & \\
\hline \multicolumn{7}{|c|}{ Postoperative complications } \\
\hline No & 16 & $64 \%$ & 19 & $76 \%$ & \multirow[t]{5}{*}{0.2} & \multirow[t]{5}{*}{ NS } \\
\hline Blood transfusion & 4 & $16 \%$ & 3 & $12 \%$ & & \\
\hline Fever & 2 & $8 \%$ & 3 & $12 \%$ & & \\
\hline Wound infection & 2 & $8 \%$ & 0 & $0 \%$ & & \\
\hline Urine leakage & 1 & $4 \%$ & 0 & $0 \%$ & & \\
\hline \multicolumn{7}{|c|}{ Postoperative complications grades (modified Clavien) } \\
\hline Grade 0 & 16 & $64 \%$ & 19 & $76 \%$ & \multirow[t]{4}{*}{0.6} & \multirow[t]{4}{*}{ NS } \\
\hline Grade 1 & 4 & $16 \%$ & 3 & $12 \%$ & & \\
\hline Grade 2 & 4 & $16 \%$ & 3 & $12 \%$ & & \\
\hline Grade 3 & 1 & $4 \%$ & 0 & $0 \%$ & & \\
\hline
\end{tabular}

Table 4: Comparisons of complications for both groups.

\begin{tabular}{|c|c|c|c|c|c|c|}
\hline \multirow[t]{2}{*}{ Variables } & \multicolumn{2}{|c|}{ Group I } & \multicolumn{2}{|c|}{ Group II } & \multirow[t]{2}{*}{ p-value } & \multirow[t]{2}{*}{ Sig } \\
\hline & \multicolumn{2}{|c|}{ OSS $(n=25)$} & \multicolumn{2}{|c|}{ PCNL(n=25) } & & \\
\hline \multicolumn{7}{|c|}{ Need for auxiliary procedures } \\
\hline No & 23 & $92 \%$ & 21 & $84 \%$ & 0.5 & NS \\
\hline SWL & 2 & $8 \%$ & 3 & $12 \%$ & & \\
\hline 2nd look PCNL & --- & --- & 1 & $4 \%$ & & \\
\hline \multicolumn{7}{|c|}{ Residual stone } \\
\hline No & 23 & $92 \%$ & 21 & $84 \%$ & 0.4 & NS \\
\hline Yes & 2 & $8 \%$ & 3 & $12 \%$ & & \\
\hline \multicolumn{7}{|c|}{ Other outcomes } \\
\hline Hospital Stay (day) & 5.88 & 1.2 & 3.92 & 1.3 & $<0.001$ & HS \\
\hline Recovery time (week) & 4.48 & 0.71 & 2.33 & 0.48 & $<0.001$ & HS \\
\hline
\end{tabular}

Table 5: Comparison of postoperative assessment and outcomes for both groups. 


\section{DISCUSSION}

According to EAU guidelines on urolithiasis (2019), advances in endourological surgery (including ureterorenoscopy (URS) and PNL) and extracorporeal shockwave lithotripsy (ESWL) have significantly decreased the indications for open stone surgery. ${ }^{78}$,

Now there is a consensus that most of complex stones (partial and complete staghorn stones), should be managed primarily by PNL. Additionally, the combined approach with PCNL and retrograde internal surgery considered an appropriate alternative. However, if percutaneous approaches are not likely to be successful, or if multiple endourological approaches have been performed unsuccessfully; so open or laparoscopic surgery can be a valid option for treatment. ${ }^{9}$

Most urological centers worldwide, with the modern equipments, expertise and experience in the surgical treatment of urinary stones, report that the incidence of open surgery in range of 1 to $5.4 \%$ of the cases. ${ }^{8}$, $9,10,11,12,13$ In UK the frequency of OSS was $1 \% .{ }^{14}$ In developing countries, like in China, that rate of OSS is increased to $7.4 \%$ in their series. ${ }^{15}$ In Pakistan, the reported rate of OSS in pediatrics is about $70 \%{ }^{16}$

As some patients are still candidates for OSS, the appropriate selection of them is mandatory to get the optimal surgical outcomes. The indications of OSS are patients with unresolved pyuria, anatomical anomalies and complex staghorn stones. Also, In cases with impaired drainage of urine due to anatomical abnormalities, as in cases with infundibular stenosis, diverticular stone, accompanied ureteropelvic junction obstruction or stricture, or in cases with skeletal deformities such as contractures or fixed deformities of the hips and legs, or in patients with history of previous kidney surgery, nonfunctioning polar segment, or nonfunctioning kidney, OSS considered a valuable option for management for their stones. ${ }^{7,17}$ While in patients with moderate stone burden with no anatomical abnormalities the PNL became the first choice. ${ }^{17}$

To assess the stone burden several stone parameters were used as the cumulative diameter, surface area and volume. In our study we used the longest stone diameter as indicator for stone size. ${ }^{18}$

Regarding the operative time, Ismail and colleagues (19) reported that operative time was $(170 \pm 32.9$ minutes) in open surgery and was significantly less than PNL (210 \pm 59.3 minutes) with P-value $<.01$ which agrees with our results.

Regarding the stone-clearance, Al-Kohlany et al reported that OSS had better outcome than PNL (82.2\% vs $74.4 \%$ ) with no significant difference. (17) Also, Zhang et al 2017 reported (97.5\% vs $76.1 \%$ ) with P-value $<0.001$.(20) Our study results agree with previous results where stone-clearance (defined as no residual stones $>4 \mathrm{ml}$ ) was (92\%) for OSS and was (84\%) for PNL with no significant difference .

Concerning the residual stones and need for auxiliary procedures, the study of Al-Kohlany et al reported the need for auxiliary procedures in $(17.8 \%$ vs $25.6 \%$ ) in OSS vs PNL groups respectively with no significant difference. ${ }^{17}$ Our results agree with the previous results where (OSS) group had Residual stones (8\%) and need auxiliary ESWL. PNL group had (16\%) residual stones and need auxiliary ESWL (12\%) and one patient need 2nd look PNL (4\%) with no significant difference .

Regarding the intraoperative and postoperative complications, Ismail et al revealed that the rate of intraoperative and postoperative complications was lower for PNL vs OSS group which was $(27.4 \%$ vs $32.1 \%)$ and $(10.4 \%$ vs $11 \%)$ with no significant difference. ${ }^{19}$

Also, Al-Kohlany et al reported that intraoperative and postoperative complication rate in OSS group was $37.8 \%$ and $31.1 \%$ which were significantly higher than PNL group where complications were $16.3 \%$ and $18.7 \%$ with P-value $0.047 .{ }^{17} \backslash$

Our study agrees with previous studies where incidence of intraoperative complications was higher in OSS group (28\%) included significant bleeding in $(16 \%)$ and pleural injury in (12\%) and in PNL group was (24\%) included bleeding (12\%) and renal pelvis injury (12\%) with no significant difference. Also, our study results agree with previous studies which revealed more postoperative complications in the (OSS) group (36\%) including (16\%) blood transfusion, (8\%) fever, $(8 \%)$ wound infection and (4\%) urine leakage while, in (PNL) group, it showed (24\%) complications including (12\%) blood transfusion and fever (12\%), with no significant difference .

As regard the classifications of the postoperative complications according to modified Clavien system in 2004, the minor grades include (grade I \& II) and the major Grades include (grade III, IV, \& V). In Zhang et al study, the minor grades for OSS were (45.5\%) and for PCNL (45.9\%).The major Grades for OSS were $(9.1 \%)$ and for PCNL (9.8\%) with no significance difference. ${ }^{20}$

In Al-Kohlany study, the minor grades for OSS were (11.1\%) and for PCNL (7\%) with no significance difference. The major Grades for OSS were (20\%) and significantly less in PCNL (10,7\%) with no significance difference. ${ }^{17}$

Our study results according to modified Clavien system showed that the minor complications in OSS were $(32 \%)$ and in PCNL were (24\%). Major complications in OSS were (4\%) and no major grades in PCNL with no significant difference .

The reported mean hospital stay and mean time required for return to normal daily activities are in accordance with those reported in the literature. Alivizatos and Skolarikos reported shorter hospital 
stay for PNL vs OSS (6.4 \pm 4.2 days) compared with (10 \pm 4.2 days) with P-value $<0.001$.

Al-Kohlany et al revealed that hospital stay was significantly shorter in the PCNL group(6.4 4.2 days) vs (10 \pm 4.2 days) for OSS with P-value $>0.001$.(17) Also, they reported that mean recovery time was significantly less in the PCNL group(17.5 \pm 5.6 days) vs (28.7 7 days) for OSS group with Pvalue $<0.001$. Ismail et al reported a significantly longer time to return to ordinary activity for OSS (21.7 \pm 4.4days) than PCNL (15.4 \pm 3.8 days) with $\mathrm{P}$ - value $<0.01 .{ }^{19}$

Our study results agrees with previous results where the patients had significantly shorter mean postoperative hospital stay in PCNL group ( $3.92 \pm$ 1.3 days) vs (5.88 \pm 1.2 days) for OSS group with $\mathrm{P}$ value $<0.001$. The mean recovery time was also significantly less in the PCNL group (16.3 \pm 3 .3days) vs (31 \pm 5 days) for OSS group with P-value $<0.001$.

The major strength of this study lies in its randomized prospective nature. In addition, the procedures were performed by experienced urosurgeons who have at least 20 years of experience. However, there are some limitations of this study. The small number of patients in each group and the use of longest dimension to measure the staghorn stones size are inherent limitation of this study. In the two groups, plain films and US were used for residual stones detection despite a more sensitive modality such as CT scan. Short term follow up is a topic that merits further investigation. It is noteworthy that we did not use flexible scopes during PCNL which may affects the overall stonefree rate.

\section{CONCLUSION}

Considering the better performance of PNL regarding safety outcomes and the better performance of OSS regarding the efficacy outcomes, both OSS and PNL are viable options for staghorn stones management.

\section{REFERENCES}

1. Healy KA, Ogan K. Pathophysiology and Management of Infectious Staghorn Calculi. Urologic Clinics of North America. 2007 Aug 1;34(3):363-74 .

2. Preminger Glenn M., Assimos Dean G., Lingeman James E., Nakada Stephen Y., Pearle Margaret S., Wolf J. Stuart. Chapter 1: aua guideline on management of staghorn calculi: diagnosis and treatment recommendations. Journal of Urology. 2005 Jun 1;173(6):1991-2000 .

3. Rieu P. Lithiases d'infection. Annales d'Urologie. 2005 Feb 1;39(1):16-29.

4. Resnick MI, Boyce WH. Bilateral Staghorn Calculi-Patient Evaluation and Management. The Journal of Urology. 1980 Mar 1;123(3):338-41 .

5. Blandy John P., Singh Manmeet. The Case for a More Aggressive Approach to Staghorn Stones. Journal of Urology. 1976 May 1;115(5):505-6
6. Honeck P, Wendt-Nordahl G, Krombach P, Bach T, Häcker A, Alken P, et al. Does Open Stone Surgery Still Play a Role in the Treatment of Urolithiasis? Data of a Primary Urolithiasis Center. Journal of Endourology. 2009 Jun 19;23(7):1209-12

7. Alivizatos G, Skolarikos A. Is there still a role for open surgery in the management of renal stones? Current Opinion in Urology. 2006 Mar;16(2):106111.

8. Assimos DG, Boyce WH, Harrison LH, McCullough DL, Kroovand RL, Sweat KR. The Role of Open Stone Surgery Since Extracorporeal Shock Wave Lithotripsy. The Journal of Urology. 1989 Aug 1;142(2, Part 1):263-7 .

9. Hyams ES, Bruhn A, Lipkin M, Shah O. Heterogeneity in the Reporting of Disease Characteristics and Treatment Outcomes in Studies Evaluating Treatments for Nephrolithiasis. Journal of Endourology. 2010 Jul 14;24(9):14114 .

10. Singh V, Sinha RJ, Gupta DK, Pandey M. Prospective Randomized Comparison of Retroperitoneoscopic Pyelolithotomy versus Percutaneous Nephrolithotomy for Solitary Large Pelvic Kidney Stones. UIN. 2014;92(4):392-5 .

11. Paik Michael L., Wainstein Mark A., Spirnak J. Patrick, Hampel Nehemia, Resnick Martin I. Current indications for open stone surgery in the treatment of renal and ureteral calculi. Journal of Urology. 1998 Feb 1;159(2):374-9 .

12. Rocco, Casu, Carmignani, Trinchieri, Mandressi, Larcher, et al. Long-term results of intrarenal surgery for branched calculi: is such surgery still valid? British Journal of Urology. 1998 Jun 1;81(6):796-800 .

13. Segura J. Role of percutaneous procedures in the management of renal calculi. Urol Clin North Am. 1990 Feb 1;17(1):207-16.

14. Buchholz NN, Hitchings A, Albanis S. The (Soon Forgotten) Art of Open Stone Surgery: To Train or Not To Train? annals. 2006 Mar 1;88(2):214-7 .

15. Yan S, Wei Q. [Open stone surgery: is it justified in the era of minimally invasive therapies?]. Zhonghua Wai Ke Za Zhi. 2009 Feb 1;47(4):2447 .

16. Rizvi S.a.h., Naqvi S.a.a., Hussain Z., Hashmi A., Hussain M., Zafar M.n., et al. Management of Pediatric Urolithiasis in Pakistan: Experience With 1,440 Children. Journal of Urology. 2003 Feb 1;169(2):634-7.

17. Al-Kohlany Khaled M., Shokeir Ahmed A., Mosbah Ahmed, Mohsen Tarek, Shoma Ahmed M., Eraky Ibrahim, et al. Treatment of complete staghorn stones: a prospective randomized comparison of open surgery versus percutaneous nephrolithotomy. Journal of Urology. 2005 Feb 1;173(2):469-73 . 
18. Lam H. Shang, Lingeman James E., Barron Michael, Newman Daniel M., Mosbaugh Phillip G., Steele Ronald E., et al. Staghorn Calculi: Analysis of Treatment Results between Initial Percutaneous Nephrostolithotomy and Extracorporeal Shock Wave Lithotripsy Monotherapy with Reference to Surface Area. Journal of Urology. 1992 May 1;147(5):1219-25 .

19. Ismail S, Ali M, Ghobashy E, Elleithy T, El-Baz A, Roushdy $M$, et al. Open Surgery in the Management of Multiple and Staghorn Kidney Stones: Its Role in the Era of Minimally Invasive Techniques Open Surgery in the Management of Multiple and Staghorn Kidney Stones: Its Role in the Era of Minimally Invasive Techniques. UroToday International Journal. 2008 Oct 4; Vol 1 / / October:1939-48 .

20. Zhang FB-Y, Lin W-R, Yang S, Hsu J-M, Chang $\mathrm{H}-\mathrm{K}$, Chen $\mathrm{M}$, et al. Outcomes of percutaneous nephrolithotomy versus open stone surgery for patients with staghorn calculi. Urological Science. 2017 Jun 1;28(2):97-100 . 